\title{
DESLIZAMIENTO LAS TORRES, VOLCÁN IRAZÚ, COSTA RICA: DEFINICIÓN DE SU VOLUMEN Y SU DIRECCIÓN PREFERENCIAL DE MOVIMIENTO
}

\author{
LAS TORRES LANDSLIDE AT IRAZÚ VOLCANO, COSTA RICA: VOLUME \\ ESTIMATION AND PREFERRED DIRECTION OF MOVEMENT
}

\author{
Rolando Mora $^{1 *}$ y Marina Pirulli ${ }^{2}$ \\ ${ }^{1}$ Escuela Centroamericana de Geología, Universidad de Costa Rica. Apartado: \\ 2142060 UCR, San Pedro, Montes de Oca, San José, Costa Rica \\ ${ }^{2}$ Politecnico di Torino, Dipartimento di Ingegneria Strutturale, Edile e Geotecnica \\ *Autor para contacto: rmorach@gmail.com
}

(Recibido: 26/10/2016; aceptado: 14/03/2017)

\begin{abstract}
A study on slope instability has been made in the western sector of Irazú volcano, which comprises the definition of the geomorphological framework, the application of finite element technique known as shear resistance reduction, to analyze the stability of the sector defined as in process of destabilization and to stablish the volume of the potential landslide. Río Sucio Oeste Active Landslide $\left(\mathrm{DA}_{\mathrm{RSO}}\right)$ was identified as the only active slide in the studied sector. In addition, it has been established that Retes Inactive Landslide $\left(\mathrm{DI}_{\mathrm{R}}\right)$ shows evidence of reactivation in the sector of its main escarpment. Moreover, it is not expected that DSPD landform presents a movement to the southwest in the future and the deformations shown by the model of a northwestward detachment become significant once the properties of shear strength are reduced by a factor of around 1.30; thus developing the collapse of the slope towards the northwest. If it is considered that the safety factor has a value of around 1.30, there must be a triggering factor for the landslide to develop. Finally, the volume of the landslide is estimated as 7 million cubic meters.

Keywords: Slope instability, land forms, finite element, shear strength reduction; Irazú volcano.
\end{abstract}

RESUMEN: Se ha efectuado un estudio de inestabilidad de laderas en el sector oeste del volcán Irazú, el cual comprende la definición de un marco geomorfológico, la aplicación de la técnica de elementos finitos conocida como reducción de la resistencia al corte, para analizar la estabilidad del sector definido como en proceso de desestabilización y la definición del volumen de material potencialmente deslizable. El Deslizamiento Activo Río Sucio Oeste $\left(\mathrm{DA}_{\mathrm{RSO}}\right)$ se identificó como el único deslizamiento activo en el sector estudiado. Adicionalmente, se ha establecido que el Deslizamiento Inactivo Retes $\left(D_{R}\right)$ muestra evidencias de reactivación en el sector de su escarpe principal. Por otra parte, no se espera que la geoforma DSPD presente un movimiento hacia el suroeste en el futuro y las deformaciones mostradas por el modelo de un desprendimiento hacia el noroeste se tornan significativas una vez que a las propiedades de resistencia al corte se les

Mora, R. y Pirulli, M. (2017). Deslizamiento Las Torres, volcán Irazú, Costa Rica: definición de su volumen y su dirección preferencial de movimiento. Revista Geológica de América Central, 56, 51-67. Doi: 10.15517/RGAC.V0I56.29236 
aplica un factor de reducción de 1,30; desarrollándose el colapso de la ladera en una dirección de deslizamiento hacia el noroeste. Si se considera que el factor de seguridad es de alrededor de 1,30, se debe contar con un factor de disparo para que el deslizamiento se desarrolle. Finalmente, el volumen del deslizamiento se estima en 7 millones de metros cúbicos. Palabras clave: Inestabilidad de laderas, formas del terreno, elementos finitos, reducción de la resistencia al corte; volcán Irazú.

\section{INTRODUCCIÓN}

El deslizamiento Las Torres se localiza en el flanco oeste del Volcán Irazú (Fig. 1), en la Provincia de Cartago, Costa Rica. Este proceso de inestabilidad de laderas es de primordial importancia ya que involucra un sector del macizo del Volcán Irazú, donde se ha instalado una gran cantidad de torres de telecomunicaciones. El edificio volcánico del Irazú es un sitio estratégico para las telecomunicaciones, pues el mismo tiene una altura cercana a los 3500 m s.n.m, lo cual favorece la transmisión de señales hacia todo el territorio nacional.

Adicionalmente, el Volcán Irazú es un volcán activo, su último período eruptivo lo presentó de 1963 a 1965, y desde entonces se ha desarrollado un proceso de instalación de torres de telecomunicaciones en su cima. Desde la perspectiva de las amenazas naturales, el sitio donde se han instalado las torres se encuentra rodeado por sectores con procesos masivos de inestabilidad de laderas, además, a una distancia en línea recta de 10,5 km en dirección Noreste se encuentra otro volcán activo, el volcán Turrialba. Lo anterior claramente establece que el lugar no es el más afortunado si lo analizamos con un criterio estrictamente preventivo.

En el presente trabajo se ha realizado la definición del marco geomorfológico en que se ubica el deslizamiento estudiado y el modelamiento del proceso de deslizamiento, con la intención de definir en qué dirección se moverá en el futuro y cuál será el volumen de material que se desplace. Para alcanzar estos propósitos se ha recurrido a la implementación de un modelo de elementos finitos de la ladera oeste del volcán Irazú y a la aplicación de la técnica de reducción de la resistencia al esfuerzo cortante (SSR por sus siglas en inglés).
En la figura 2 se puede apreciar una vista satelital oblicua del sector donde se ha desarrollado esta investigación.

\section{MARCO GEOMORFOLÓGICO}

A continuación se realiza una descripción de las formas/unidades geomorfológicas identificadas en el sector estudiado (Fig. 3), la cual se aborda desde el punto genético de las geoformas y siguiendo los principios básicos de la clasificación geomorfológica propuesta por van Zuidam (1986).

\section{Formas/unidades de origen denudacional}

Deslizamiento Activo Río Sucio Oeste $\left(\mathrm{DA}_{\mathrm{RSO}}\right)$ : Deslizamiento activo del tipo compuesto, que involucra desprendimientos traslacionales y flujos de lodo y rocas, el cual se ha desarrollado a través de rupturas retrogresivas de materiales de origen volcánico (cenizas, tobas, lavas), los cuales en ocasiones presentan una notoria alteración hidrotermal. Este deslizamiento se identificó como el único deslizamiento activo en el sector estudiado mediante la interpretación de imágenes satelitales de Google Earth, el mismo se desarrolla en la cabecera oeste del río Sucio (Figs. 4 y 5) y se le conoce como deslizamiento Las Torres.

Deslizamiento inactivo Río Sucio Norte $\left(\mathrm{DI}_{\mathrm{RSN}}\right)$ : Deslizamiento inactivo del tipo compuesto, localizado al norte del sector de Las Torres. Actualmente no muestra evidencias de movimiento y se encuentra cubierto por vegetación densa tipo páramo (Fig. 6). 


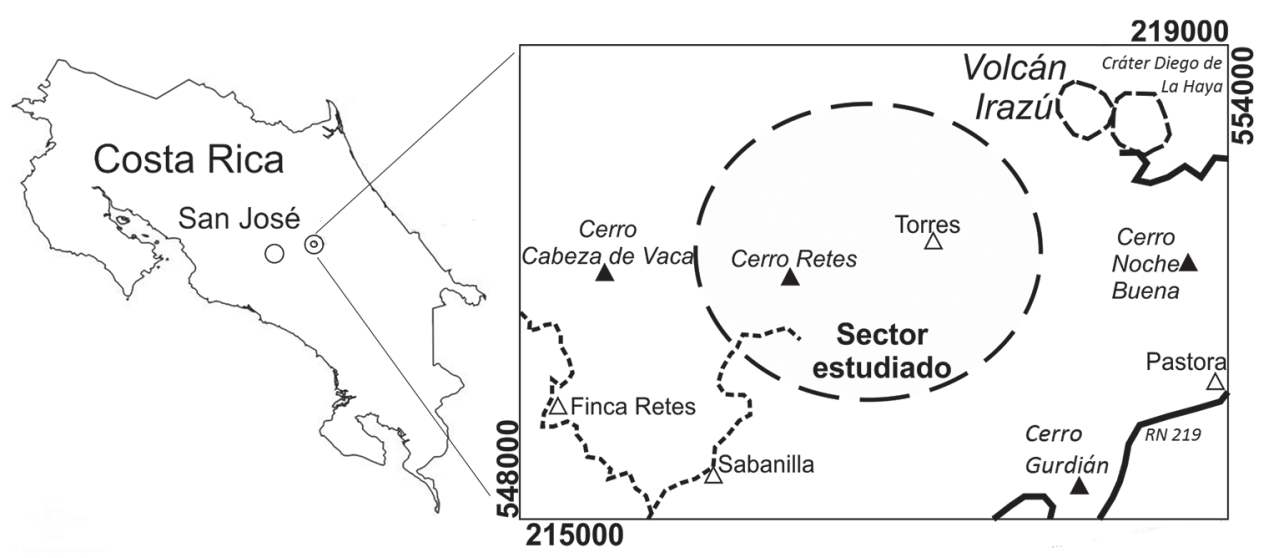

Fig. 1: Ubicación del sector estudiado al suroeste del cráter del volcán Irazú, Cartago, Costa Rica.

Deslizamiento Inactivo Retes $\left(\mathrm{DI}_{\mathrm{R}}\right)$ : Deslizamiento inactivo del tipo compuesto, localizado al suroeste del sector Las Torres. De acuerdo con la interpretación de las imágenes satelitales, este deslizamiento no muestra evidencias de movimiento y se encuentra cubierto por vegetación tipo páramo y un bosque de ciprés, eucalipto y otras especies de árboles (Fig. 7). Sin embargo, luego de la inspección de campo se pudo constatar que el deslizamiento muestra evidencias de reactivación en el sector de su escarpe principal (Fig. 8).

Bloque Deslizado $\left(\mathrm{D}_{\mathrm{BD}}\right)$ : Esta forma del terreno presenta características muy particulares, pues está bordeada al sur y al oeste por escarpes de fuerte pendiente y de menor elevación que su sección interior, hacia el este aparece otro escarpe pero de elevaciones mayores que su sección interior (Fig. 3). La sección interior presenta una pendiente hacia el sur y se asemeja a una cicatriz de deslizamiento de acuerdo con la forma de las curvas de nivel obtenidas de Google Earth (Fig. 3). Existe la posibilidad de que se trate de un deslizamiento rotacional que desarrolló un flujo hacia el sur, el cual se canalizó posteriormente hacia el noroeste y el este, siguiendo el flujo de la cabecera oeste del río Sucio. También existe la posibilidad de que se trate de un bloque deslizado y basculado, que forma parte del Deslizamiento
Activo Río Sucio Oeste (DARSO) y que sea la evidencia de la propagación retrogresiva del mismo deslizamiento (Figs. 9 y 10).

Sector en Proceso de Desestabilización $\left(\mathrm{D}_{\mathrm{SPD}}\right)$ : Este sector comprende desde el escarpe localizado en el límite con el Bloque Deslizado (DBD) al oeste, hasta donde aparecen grietas continuas en las cercanías de las torres de telecomunicaciones, las cuales indican el avance del proceso de desestabilización (Fig. 3). La incertidumbre que se genera alrededor de esta forma del terreno es hacia dónde se desplazará el material desestabilizado, pues el mismo puede orientarse hacia el Deslizamiento Inactivo Retes $\left(\mathrm{DI}_{\mathrm{R}}\right)$ o hacia el Deslizamiento Activo Río Sucio Oeste $\left(\mathrm{DA}_{\mathrm{RSO}}\right)$ (Figs. 3 y 7), esto en función del mecanismo de movimiento que se presente en el futuro. La dirección del movimiento de este sector es relevante desde la perspectiva de las implicaciones que pueda tener en materia de prevención del riesgo, pues si se desplaza hacia el Deslizamiento Activo Río Sucio Oeste $\left(\mathrm{DA}_{\mathrm{RSO}}\right)$, el material podría ser manejado por la amplitud y capacidad hidráulica de la cuenca, dentro de la cual, a $24 \mathrm{~km}$ de distancia del sector estudiado, se ubica el puente sobre el río Sucio, de la Ruta Nacional 32, que representa la vía de comunicación principal entre el Valle Central y la Región Caribe. Esta obra civil merece ser estudiada con más detalle mediante investigaciones que 


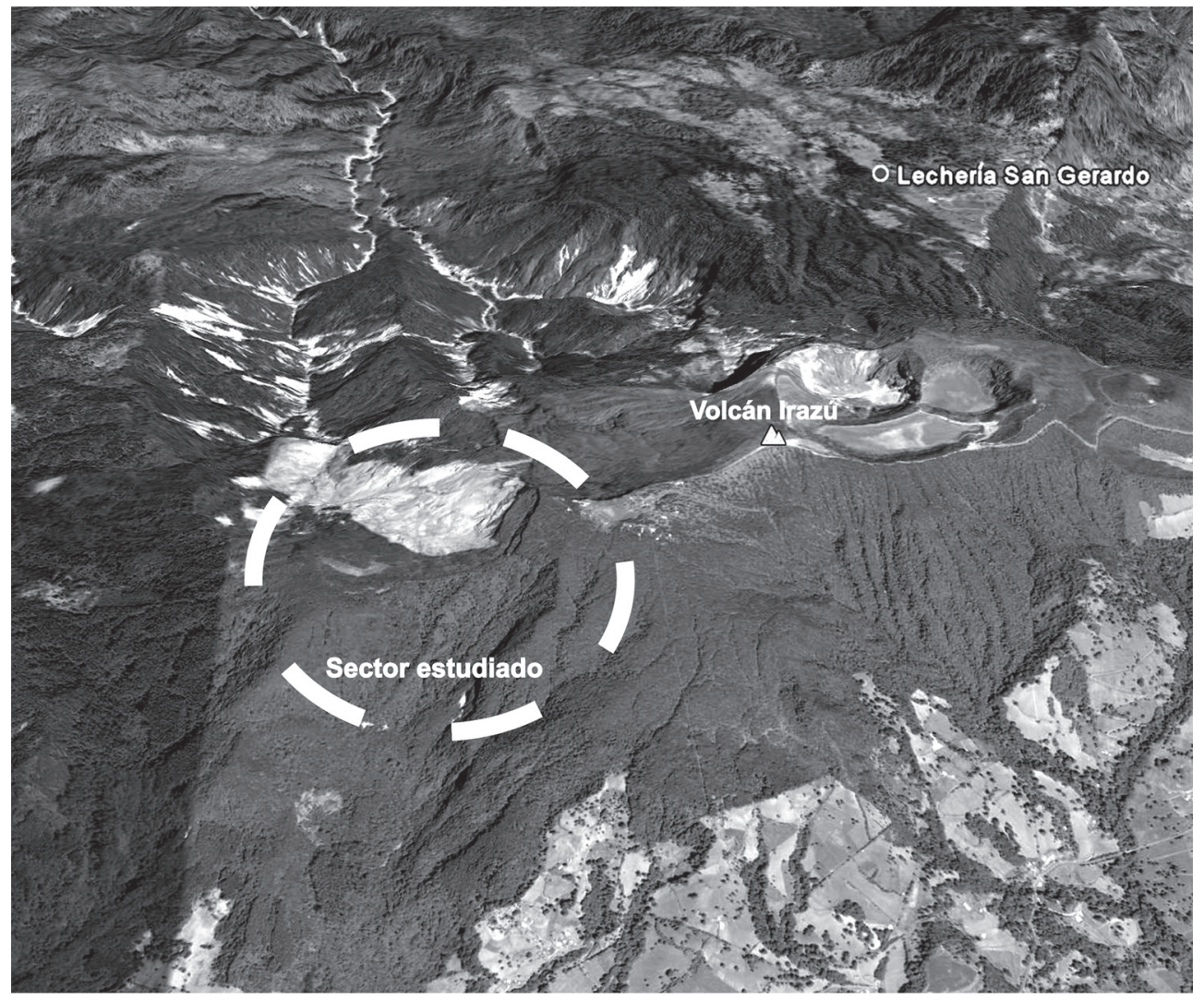

Fig. 2: Vista satelital oblicua del sector investigado (Imágenes 2015 Digital Globe, Landsat 2015 Google).

conduzcan a establecer el tirante de una eventual avalancha de lodo y rocas, y las implicaciones que esta pueda tener en la seguridad del puente. Por otro lado, si el material se desplaza hacia el Deslizamiento Inactivo Retes $\left(\mathrm{DI}_{\mathrm{R}}\right)$, el proceso de desarrollo de una avalancha o flujo de lodo y rocas por el cauce del río Reventado debería de abordarse como una situación sumamente delicada, debido a la ubicación de asentamientos humanos e importantes obras de infraestructura en el sector oeste de la ciudad de Cartago que podrían verse impactados por el evento, como se advierte en Pirulli y Mora (en prensa).

\section{Formas/unidades de origen estructural}

Faceta Triangular $\left(\mathrm{S}_{\mathrm{FT}}\right)$ : Esta forma del terreno de pendiente pronunciada, de forma triangular (Fig. 11), parece estar asociada a un alinea- 


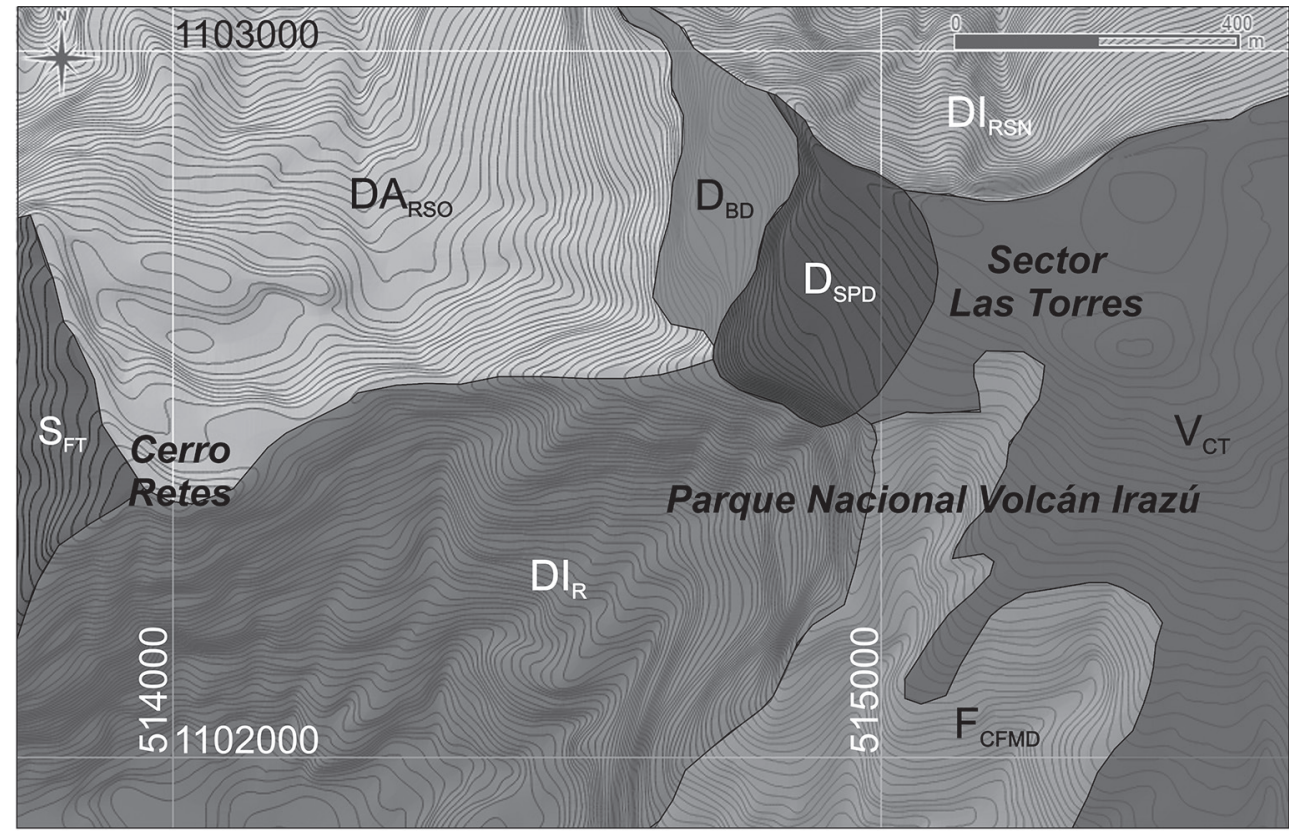

Formas/Unidades Denudacionales

$\square$ DA $_{\text {RSO }}$ Deslizamiento activo Río Sucio Oeste

$\square \mathrm{DI}_{\mathrm{RSN}}$ Deslizamiento inactivo Río Sucio Norte

$D I_{R}$ Deslizamiento inactivo Retes

$\square D_{\mathrm{BD}}$ Bloque deslizado

$D_{\text {SPD }}$ Sector en proceso de desestabilización

\section{Formas/Unidades Estructurales}

$\mathrm{S}_{\mathrm{FT}}$ Faceta triangular

\section{Formas/Unidades Volcánicas}

$V_{\text {ст }}$ Campos de tefras

\section{Formas/Unidades Fluviales}

$\square F_{\text {CFMD }}$ Cabeceras fluviales muy disectadas

Fig. 3: Geomorfología de los alrededores del sector Las Torres, volcán Irazú, Costa Rica.

miento muy claro de dirección norte-sur, el cual debe estudiarse con mucho más detalle en el futuro, pues puede tratarse de fallamiento activo en el sector estudiado.
Formas/Unidades de origen volcánico

Campos de tefras (VCT): Este es el área tapizada por los depósitos de tefras de la última erupción 


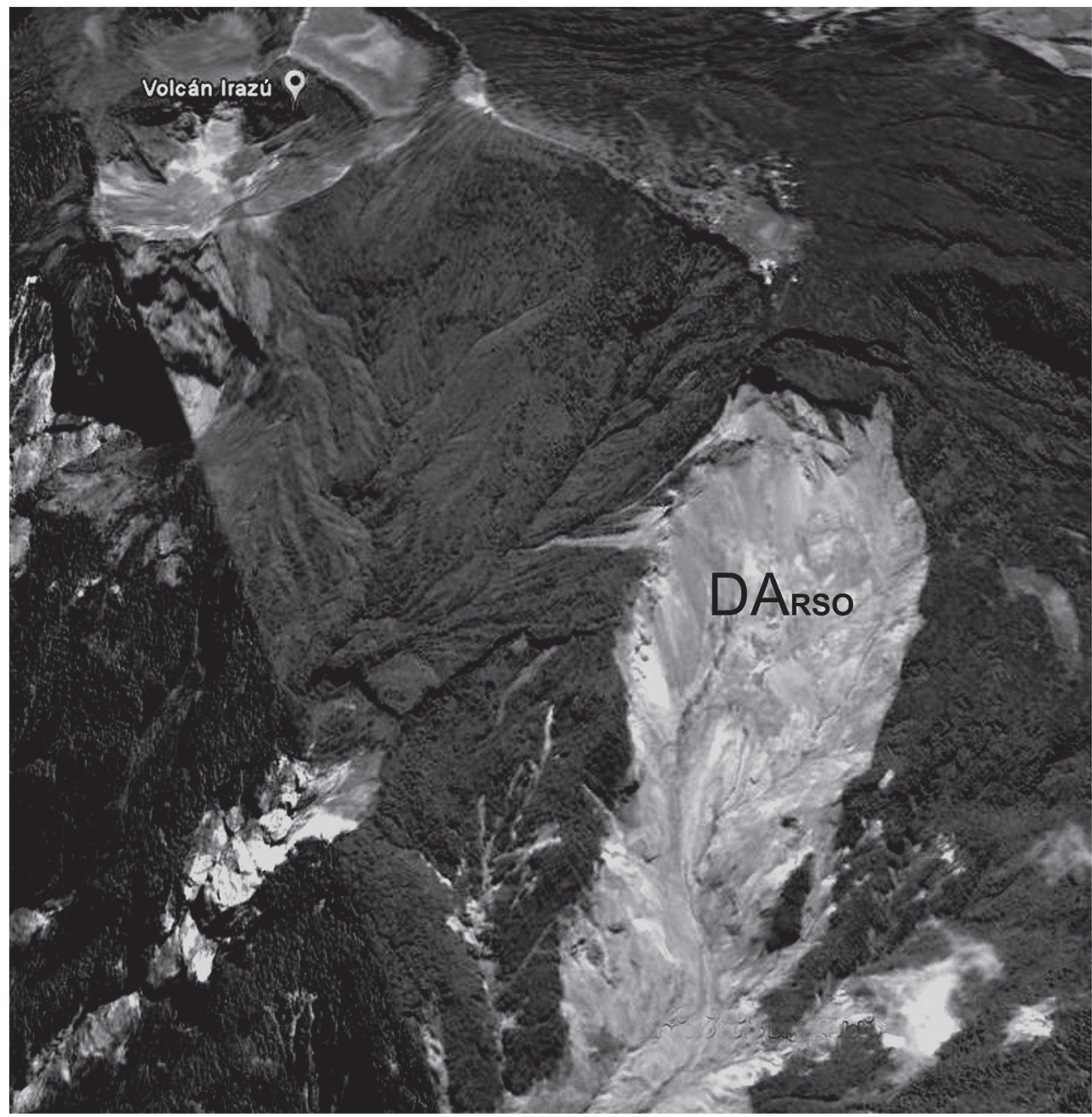

Fig. 4: Vista oblicua del Deslizamiento Activo Río Sucio Oeste ( $\mathrm{DA}_{\mathrm{RSO}}$ ) (Imágenes 2015 Digital Globe, Landsat 2015 Google).

del volcán Irazú (Fig. 3), la cual se dio de 1963 a 1965 y que se encuentra ampliamente descrita en Alvarado (2009). Las tefras en este sector no han sido afectadas por los procesos de deslizamiento, ni por erosión superficial significativa.

\section{Formas/Unidades de origen fluvial}

Cabeceras Fluviales Muy Disectadas $\left(\mathrm{F}_{\text {CFMD }}\right)$ : Sectores superiores de las cuencas que drenan hacia el sur del edificio volcánico (Fig. 3), caracterizados por el desarrollo de una incisión vertical (disección) muy importante, con la presencia de deslizamientos de tamaño y volumen pequeño, los cuales se circunscriben a los depósitos superficiales de tefras. El drenaje típico de estos sectores es dendrítico, los deslizamientos son disparados por los eventos de precipitaciones intensas, sus productos son distribuidos por las corrientes fluviales hacia las partes bajas de la cuenca. 


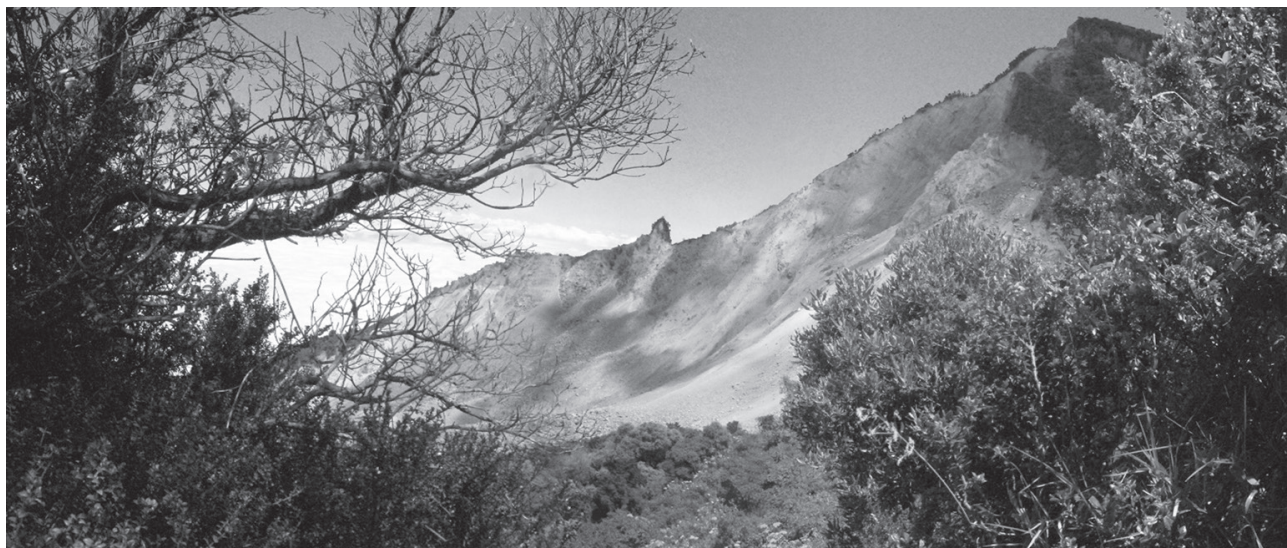

Fig. 5: Deslizamiento Activo Río Sucio Oeste $\left(\mathrm{DA}_{\mathrm{RSO}}\right)$, conocido como deslizamiento Las Torres. Imagen tomada desde el cerro Retes en Febrero de 2016.

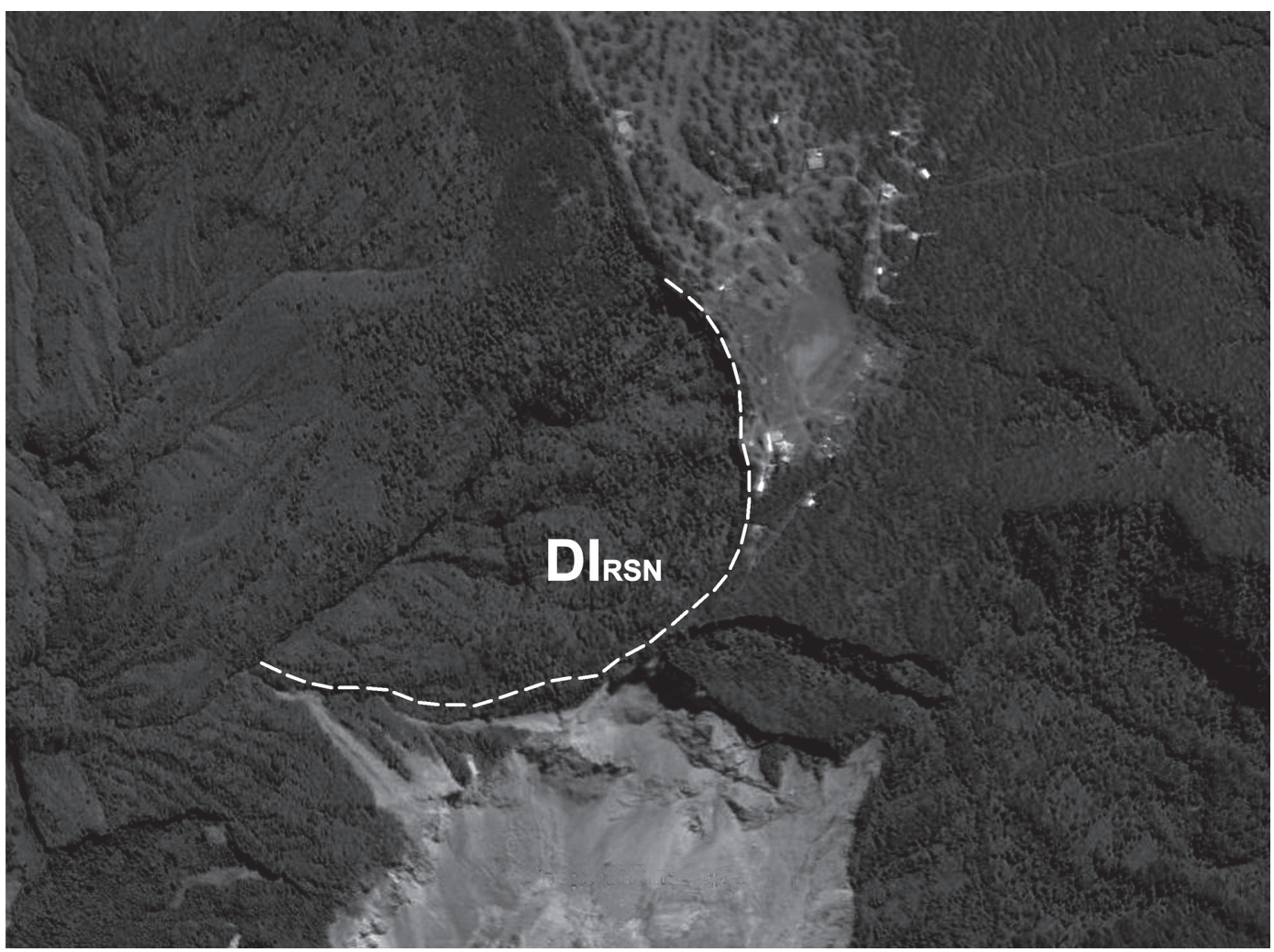

Fig. 6: Vista oblicua del Deslizamiento Inactivo Río Sucio Norte ( $\mathrm{DI}_{\mathrm{RSN}}$ ) (Imágenes 2015 Digital Globe, Landsat 2015 Google). 


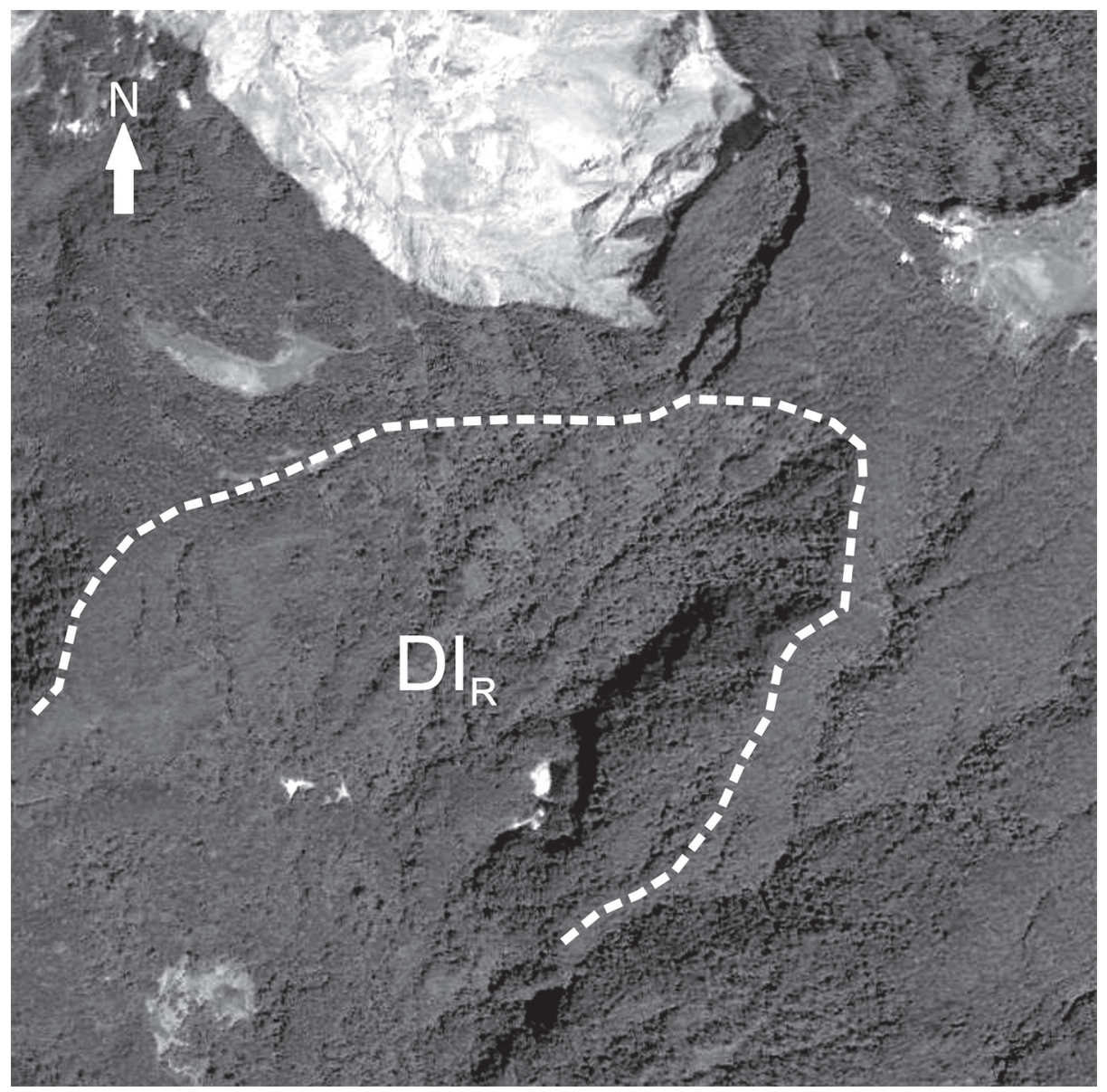

Fig. 7: Vista oblicua del Deslizamiento Inactivo Retes $\left(\mathrm{DI}_{\mathrm{R}}\right)$ (Imágenes 2015 Digital Globe, Landsat 2015 Google).

\section{LA TÉCNICA DE ELEMENTOS FINITOS CONOCIDA COMO REDUCCIÓN DE LA RESISTENCIA AL CORTE (RRC EF) APLICADA AL ANÁLISIS DE LA ESTABILIDAD DEL SECTOR EN PROCESO DE DESESTABILIZACIÓN (DSPD)}

Cuando se usa la técnica de elementos finitos RRC (SSR FE por sus siglas en inglés) se asume que los materiales que componen la ladera siguen un comportamiento elasto-plástico y sus parámetros de resistencia son progresivamente reducidos hasta que se produce un colapso (ROCSIENCE, 2004). En el caso de un material Mohr-Coulomb los parámetros efectivos de resistencia al corte se reducen utilizando un factor (de seguridad) $\mathrm{F}$ de la siguiente manera (ROCSIENCE, 2004):

$$
\begin{aligned}
& \mathrm{c}^{*}=\mathrm{c}^{\prime} / \mathrm{F} \\
& \phi^{*}=\arctan \left(\tan \phi^{\prime} / \mathrm{F}\right)
\end{aligned}
$$

Los anteriores se conocen como los parámetro de resistencia al corte Mohr-Coulomb reducidos, los cuales son utilizados para alimentar los modelos de elementos finitos de las laderas (ROCSIENCE, 2004). Los pasos para la búsqueda sistemática del valor del factor crítico de seguridad, $\mathrm{F}$, que conduce a una ladera previamente 


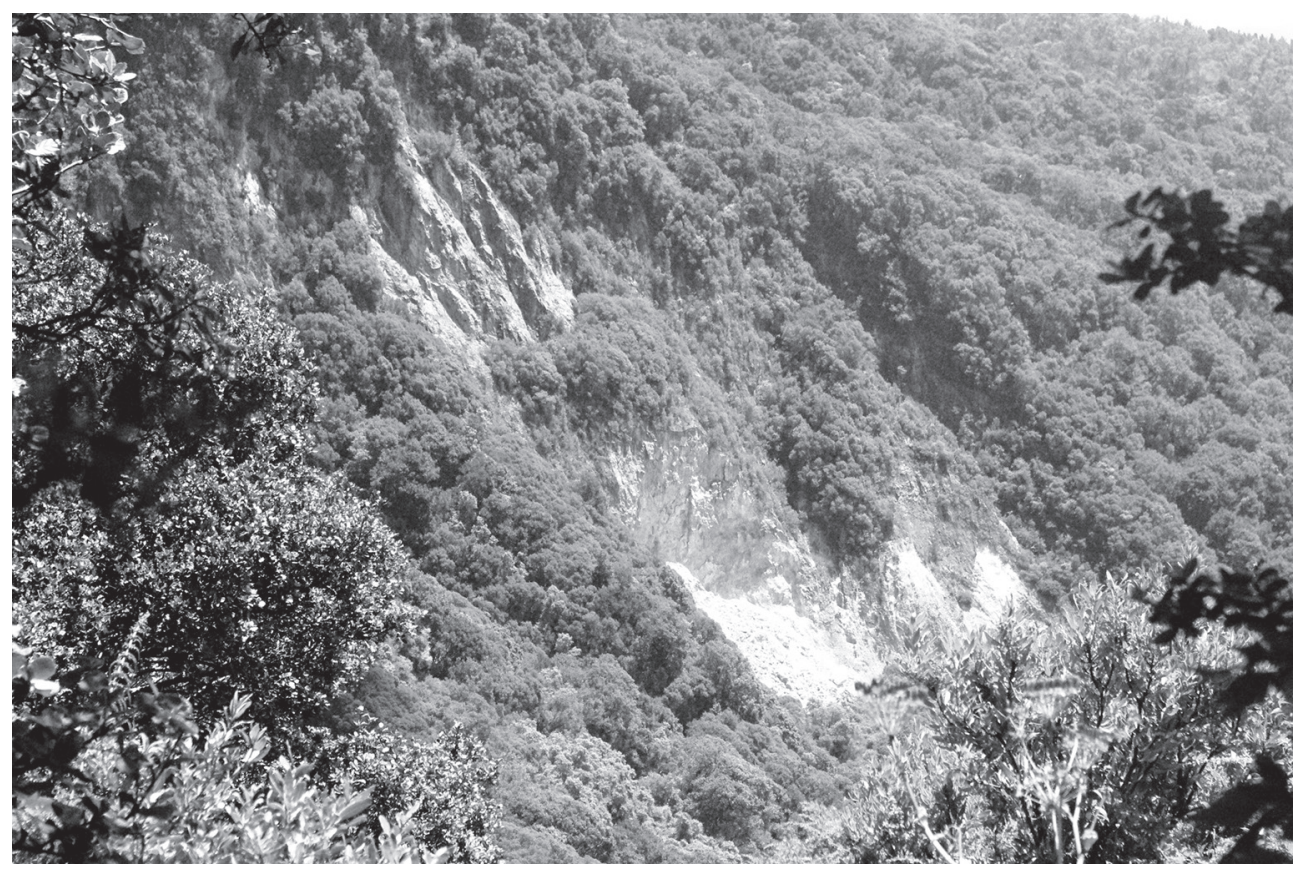

Fig. 8: Evidencias de reactivación del escarpe principal del Deslizamiento Inactivo Retes $\left(\mathrm{DI}_{\mathrm{R}}\right)$. Imagen tomada en febrero de 2016 por el autor.

estable al borde del colapso, son los siguientes (ROCSIENCE, 2004):

- Paso 1: Se desarrolla un modelo de elementos finitos (EF) de la ladera, usando los parámetros de deformación y resistencia establecidos para los materiales que la componen. Se calcula el modelo y se registra la deformación total máxima de la ladera.

- Paso 2: Se aumenta el valor de F y se calculan los parámetros del material Mohr Coulomb factorizados como se describió anteriormente. Se introducen las nuevas propiedades de resistencia en el modelo de la ladera y se procede a recalcularlo. Se registra la deformación total máxima.

- Paso 3: Se repite el paso 2, utilizando incrementos sistemáticos de $\mathrm{F}$, hasta que el modelo de EF no presente convergencia hacia una solución, es decir, se reduce la resistencia del material hasta que falle la ladera. El valor crítico de F, a partir del cual se produce el colapso, se considera el factor de seguridad de la ladera.
El enfoque elasto-plástico RRC EF (SSR FE por sus siglas en inglés) ofrece una serie de ventajas significativas sobre el análisis tradicional de equilibrio límite, ya que elimina la necesidad de suposiciones a priori sobre los mecanismos de falla (el tipo, la forma y la ubicación de las superficies de falla), estableciendo automáticamente el mecanismo de falla crítico (ROCSIENCE, 2004). Al tratarse de un método de elementos finitos, el modelamiento se puede acoplar con modelos del flujo de aguas subterráneas y de cambios en el estado de esfuerzos.

\section{Modelos de elementos finitos propuestos}

Se han desarrollado dos modelos de elementos finitos para analizar la estabilidad de la geoforma $\mathrm{D}_{\mathrm{SPD}}$, considerando que el movimiento se desarrolle hacia el sector sur, es decir, hacia la subcuenca del río Reventado, o en su defecto hacia el oeste en dirección de la cuenca del río 


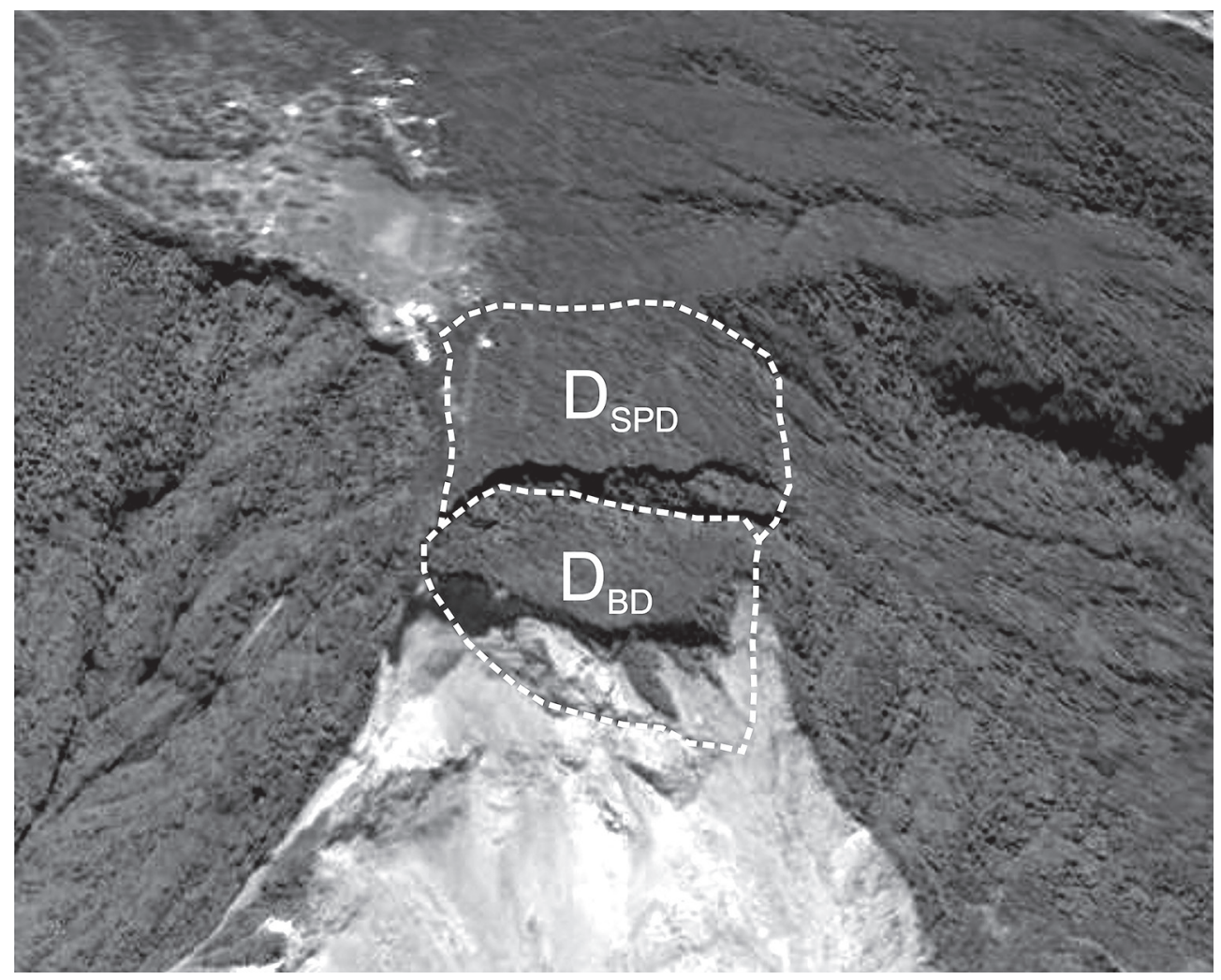

Fig. 9: Vista oblicua del Bloque deslizado $\left(\mathrm{D}_{\mathrm{BD}}\right)$ y del Sector en Proceso de Desestabilización $\left(\mathrm{D}_{\mathrm{SPD}}\right)$. (Imágenes 2015 Digital Globe, Landsat 2015 Google).

Sucio. Estas consideraciones son apropiadas ya que las curvas de nivel indican un gradiente topográfico en dirección suroeste, entonces se puede suponer que hay posibilidad de que la ruptura también se oriente en la misma dirección. Por otro lado, la actividad del deslizamiento $\mathrm{DA}_{\mathrm{RSO}}$, sugiere que el bloque $\mathrm{D}_{\mathrm{BD}}$ y el sector $\mathrm{D}_{\mathrm{SPD}}$ pueden ser la consecuencia de una propagación retrogresiva de ese deslizamiento activo y que se pueden deslizar en dirección noroeste. Los modelos se han planteado a lo largo de dos perfiles topográficos con orientación $\mathrm{N} 30^{\circ} \mathrm{E}$ y $\mathrm{N} 65^{\circ} \mathrm{W}$ respectivamente y se les han asignado los parámetros de resistencia y deformación del cuadro 1. Los parámetros asignados se han obtenido a partir de tres estudios geotécnicos realizados en la cima y el flanco sur del macizo, una gira de campo que concluyó visitando el pie del deslizamiento, así como mediante
Cuadro 1

Parámetros de resistencia y deformación asignados al modelo de elementos finitos.

\begin{tabular}{cc}
\hline Categoría de material: & Parámetros efectivos \\
\hline Modelo de material & Elasto-plástico \\
Módulo de esfuerzo-deformación & $2274710 \mathrm{kPa}$ \\
Cohesión efectiva & $490 \mathrm{kPa}$ \\
Ángulo de fricción interna & $48^{\circ}$ \\
Relación de Poisson & 0,2 \\
Peso unitario & $24 \mathrm{kN} / \mathrm{m}^{3}$ \\
\hline
\end{tabular}

el uso del programa RocLab 1.033 (ROCSIENCE, 2007), con el que se procesaron todos los datos recolectados en campo. En el cuadro 2 se presentan los datos de entrada, obtenidos mediante investigaciones de campo y pruebas de laboratorio, 


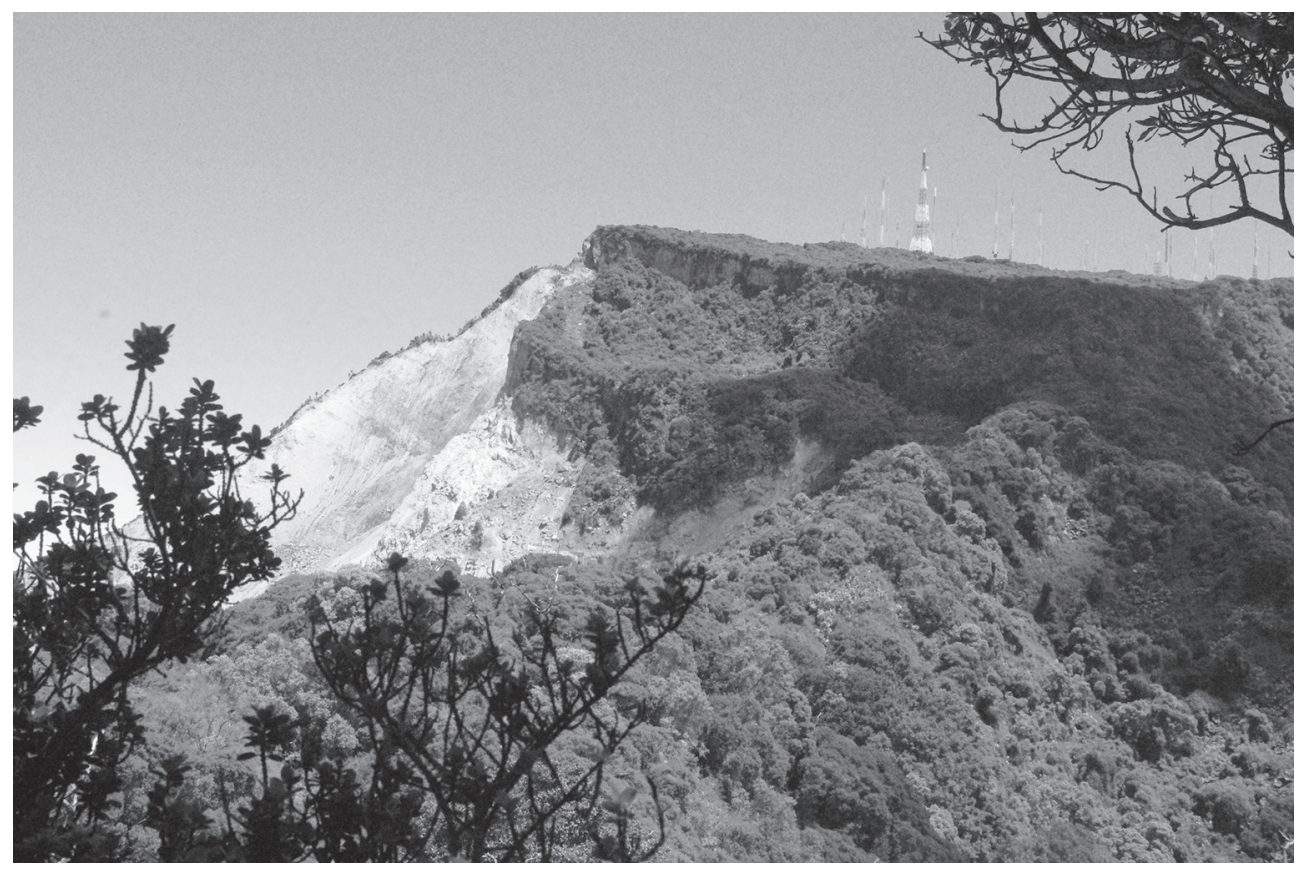

Fig. 10: Bloque deslizado $\left(\mathrm{D}_{\mathrm{BD}}\right)$ tomado desde el cerro Retes. Imagen tomada en febrero de 2016 por el autor.

\section{Cuadro 2}

Parámetros de entrada y resultados de la aplicación de RocLab 1.033 (ROCSIENCE, 2007) para el macizo rocoso estudiado.

\begin{tabular}{|c|c|c|}
\hline \multirow{5}{*}{ Classification de Hoek y Brown (2002) } & Resistencia a la compresión uniaxial & $35 \mathrm{MPa}$ \\
\hline & GSI & 37 \\
\hline & $\mathrm{mi}$ & 19 \\
\hline & $\mathrm{D}$ & 0 \\
\hline & $\mathrm{Ei}$ & $17500 \mathrm{MPa}$ \\
\hline \multirow{3}{*}{ Criterio de ruptura de Hoek y Brown (2002) } & $\mathrm{mb}$ & 2.003 \\
\hline & $\mathrm{s}$ & 0.000911882 \\
\hline & a & 0.514 \\
\hline \multirow{2}{*}{ Ajuste de Mohr-Coulomb } & $\mathrm{c}$ & $0,490 \mathrm{MPa}$ \\
\hline & $\phi$ & $47,4^{\circ}$ \\
\hline \multirow{4}{*}{ Parámetros del macizo rocoso } & Resistencia tensional & $-0.016 \mathrm{MPa}$ \\
\hline & Resistencia a la compresión uniaxial & $0.959 \mathrm{MPa}$ \\
\hline & Resistencia global & $6.307 \mathrm{MPa}$ \\
\hline & Módulo de esfuerzo-deformación & $2274.7 \mathrm{MPa}$ \\
\hline
\end{tabular}


Cuadro 3

Aplicación de la técnica SSR FE al análisis del deslizamiento de la geoforma DSPD en dirección suroeste.

\begin{tabular}{cccc}
\hline $\begin{array}{c}\text { Factor de } \\
\text { reducción }\end{array}$ & $\begin{array}{c}\mathrm{c} \\
(\mathrm{kPa})\end{array}$ & $\begin{array}{c}\phi^{\prime} \\
(\text { grados })\end{array}$ & Deformación máxima \\
\hline 1,0 & 490,0 & 48 & 0 \\
2,0 & 245,0 & 24 & 0,0014 \\
3,0 & 163,3 & 16 & 0,0326 \\
4,0 & 122,5 & 12 & 0,0746 \\
\hline
\end{tabular}

Cuadro 4

Aplicación de la técnica SSR FE al análisis del deslizamiento de la geoforma DSPD en dirección noroeste.

\begin{tabular}{cccc}
\hline $\begin{array}{c}\text { Factor de } \\
\text { reducción }\end{array}$ & $\begin{array}{c}\mathrm{c} \\
\mathrm{kPa} \text { ] }\end{array}$ & $\begin{array}{c}\phi^{\prime} \\
\text { [grados] }\end{array}$ & Deformación máxima \\
\hline 1,00 & 490,0 & 48 & 0 \\
1,20 & 408,3 & 40 & 0 \\
1,30 & 376,9 & 39,9 & 0,0008 \\
1,31 & 374,0 & 36,6 & 0,564 \\
\hline
\end{tabular}

así como, los resultados obtenidos para el macizo rocoso estudiado. La figura 12 muestra el criterio de ruptura de Hoeck y Brown (2002) y el ajuste de la envolvente de Mohr-Coulomb realizados con el programa RocLab 1.033 (ROCSIENCE, 2007) para el mismo macizo rocoso.

\section{Análisis de estabilidad considerando un desprendimiento hacia el suroeste}

Este primer modelamiento se ha ejecutado en dirección suroeste, para estudiar la posibilidad de deslizamiento de la geoforma $\mathrm{D}_{\mathrm{SPD}}$ hacia la subcuenca del río Reventado. Los resultados se resumen en el cuadro 3.

Las deformaciones mostradas por el modelo se tornan significativas una vez que las propiedades de resistencia al corte se han reducido al menos a la mitad. El modelo no presenta convergencia a partir de un factor de reducción de 4,0, es decir este es el factor de seguridad de la ladera si consideramos una dirección de deslizamiento hacia el suroeste.

El factor de seguridad es muy alto y el mecanismo de falla tendería a desarrollar rupturas más o menos circulares en la sección de mayor pendiente del perfil analizado (Fig. 13). Por lo anterior, se descarta que esta sea la tendencia del movimiento de la geoforma $\mathrm{D}_{\mathrm{SPD}}$, es decir no se espera que la geoforma $\mathrm{D}_{\mathrm{SPD}}$ presente un movimiento hacia el suroeste en el futuro.

\section{Análisis de estabilidad considerando un desprendimiento hacia el noroeste}

En este modelamiento se estudia la posibilidad de que el desprendimiento de la geoforma $\mathrm{D}_{\mathrm{SPD}}$ se dé en dirección noroeste, es decir, se manifieste como una propagación retrogresiva del deslizamiento o geoforma $\mathrm{DA}_{\mathrm{RSO}}$. Los resultados se resumen en el cuadro 4.

Las deformaciones mostradas por el modelo se tornan significativas una vez que a las propiedades de resistencia al corte se les aplica un factor de reducción de 1,30. El modelo no presenta convergencia a partir de un factor de reducción de 1,31, desarrollándose el colapso de la ladera (Figs. 14 y 15), es decir, este valor del factor de reducción corresponde con el factor de seguridad de la ladera si consideramos una dirección de deslizamiento hacia el noroeste.

Si se considera que el factor de seguridad es entonces 1,31 , se debe contar con un factor de disparo para que se desarrolle el deslizamiento. Los factores de disparo posibles pueden ser:

- Un periodo de lluvias de baja intensidad pero de duración prolongada, que propicien el desarrollo de la superficie de ruptura profunda.

- Actividad sísmica capaz de inducir aceleraciones capaces de reducir el factor de seguridad a valores cercanos o inferiores a la unidad. Es importante anotar que el Terremoto de Patillos, ocurrido el 30 de Diciembre de 1952, produjo intensidades MM de VIII en las faldas del volcán Irazú, así como, enormes deslizamientos (Montero y Alvarado, 1995)

- Una combinación de los dos factores antes mencionados 


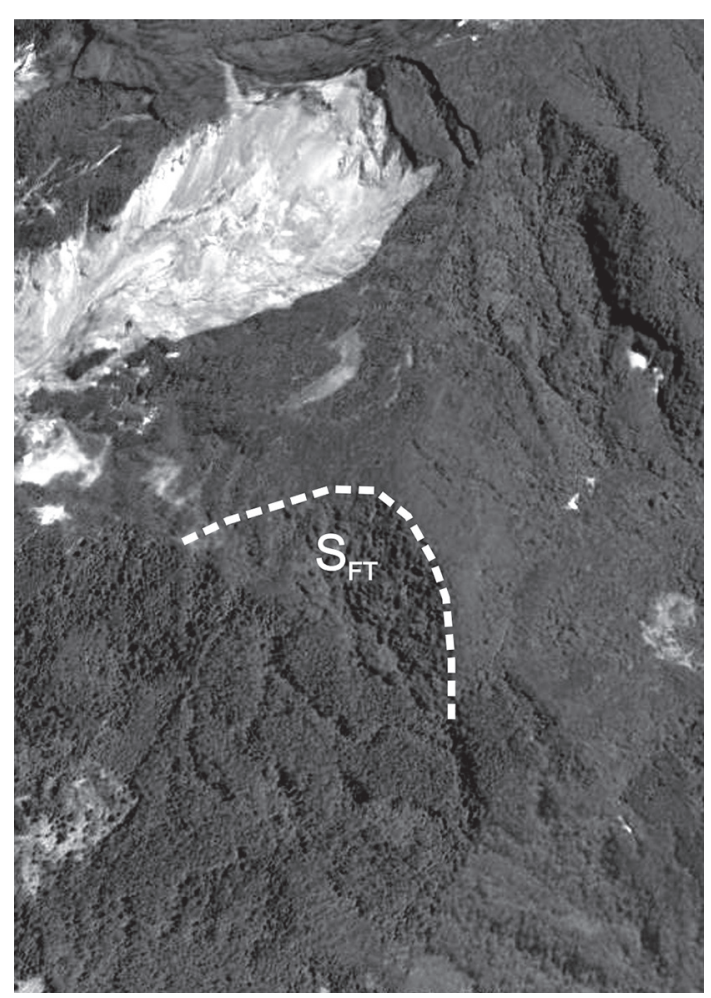

Fig. 11: Vista oblicua del Facetamiento Triangular $\left(\mathrm{S}_{\mathrm{FT}}\right)$ (Imágenes 2015 Digital Globe, Landsat 2015 Google)

\section{VOLUMEN DEL DESLIZAMIENTO MÁS PROBABLE}

Si se toma en consideración la superficie de ruptura definida en el apartado anterior y se miden las dimensiones del deslizamiento máximo posible, las cuales se introducen en la fórmula de Cruden y Varnes (1996), con la cual se estima el volumen de medio elipsoide de revolución ajustado a las dimensiones máximas (Cuadro 5). El volumen estimado es de 7 millones de metros cúbicos, el cual es un volumen que se puede considerar como normal o más bien creíble para este tipo de eventos.

\section{CONCLUSIONES}

El Deslizamiento Activo Río Sucio Oeste $\left(\mathrm{DA}_{\mathrm{RSO}}\right)$ se identificó, mediante la interpretación de imágenes satelitales, como el único deslizamiento activo en el sector estudiado.
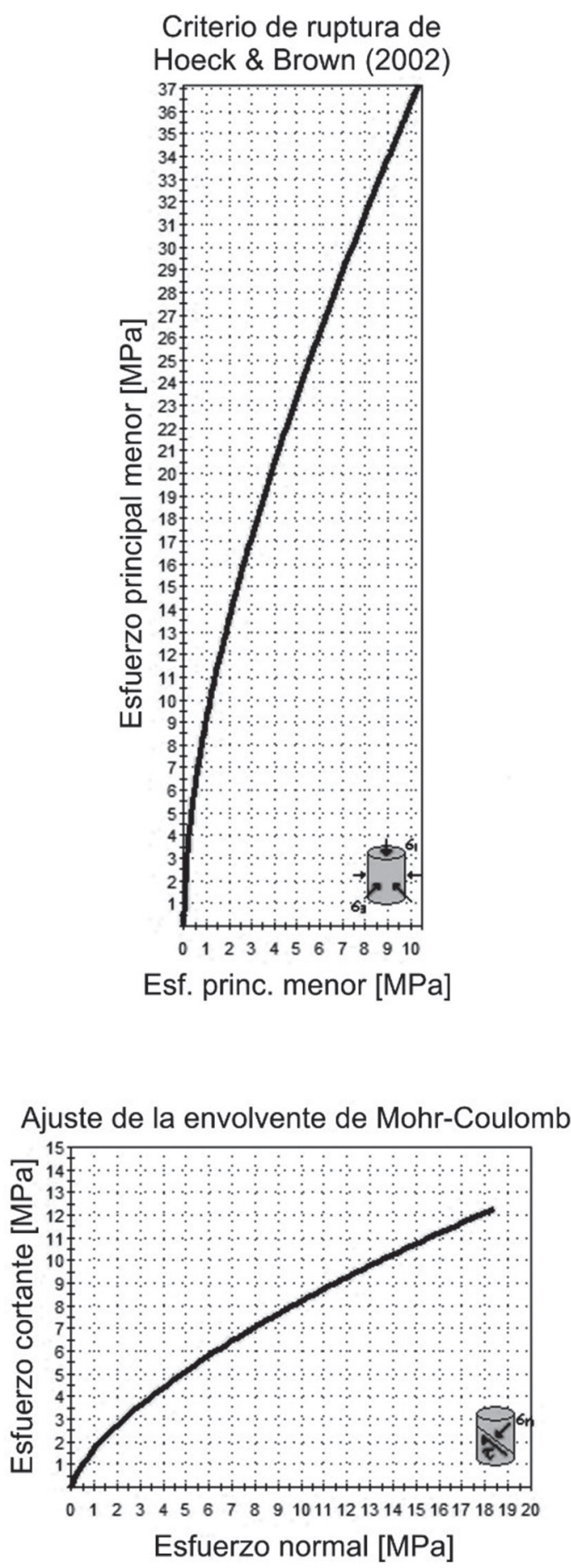

Fig. 12: Criterio de ruptura de Hoeck y Brown (2002) y ajuste de la envolvente de Mohr-Coulomb realizados con el programa RocLab 1.033 (ROCSIENCE, 2007) para el mismo macizo rocoso. 

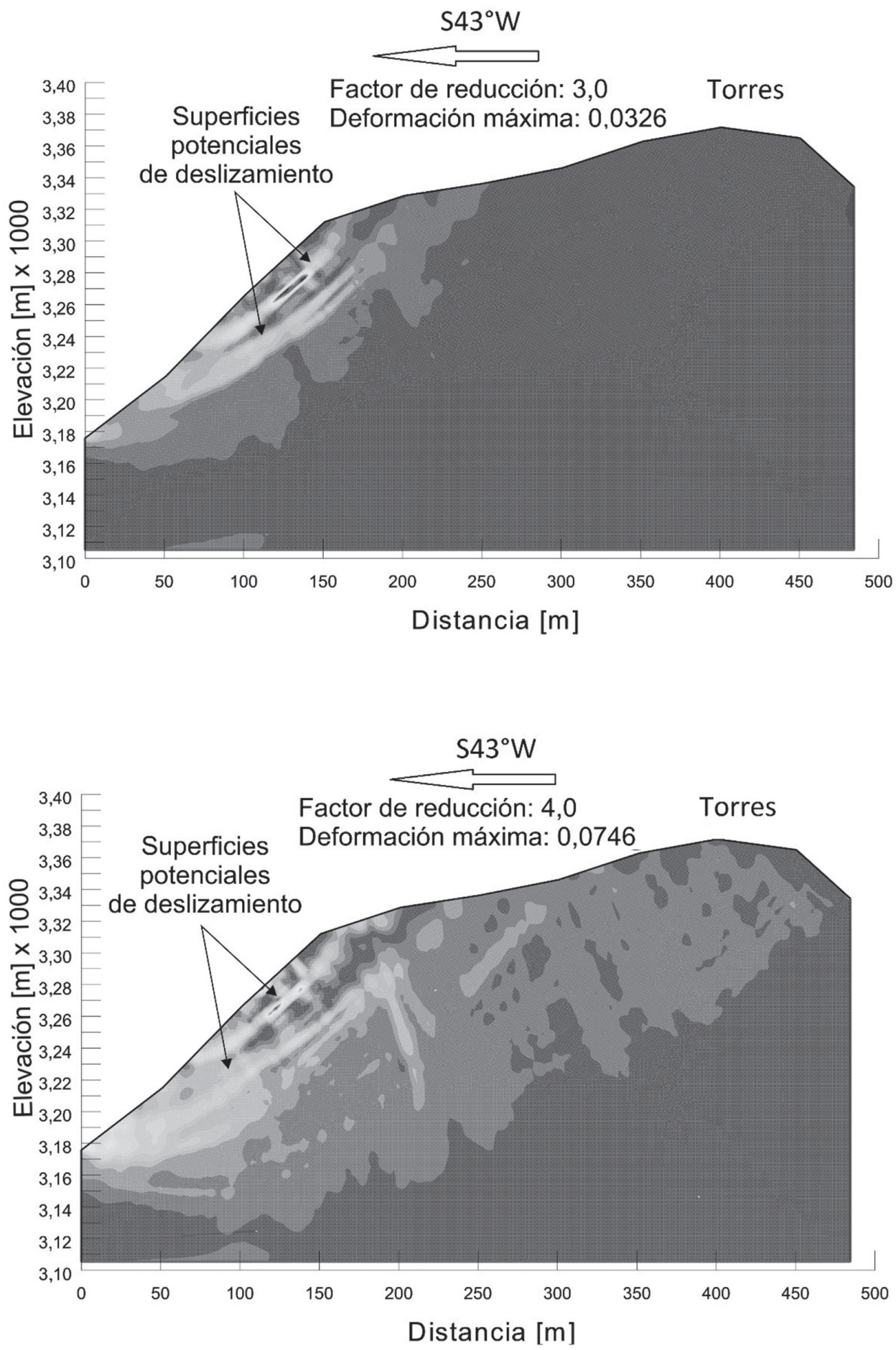

Fig. 13: Resultados del análisis de estabilidad considerando un desprendimiento hacia el suroeste 


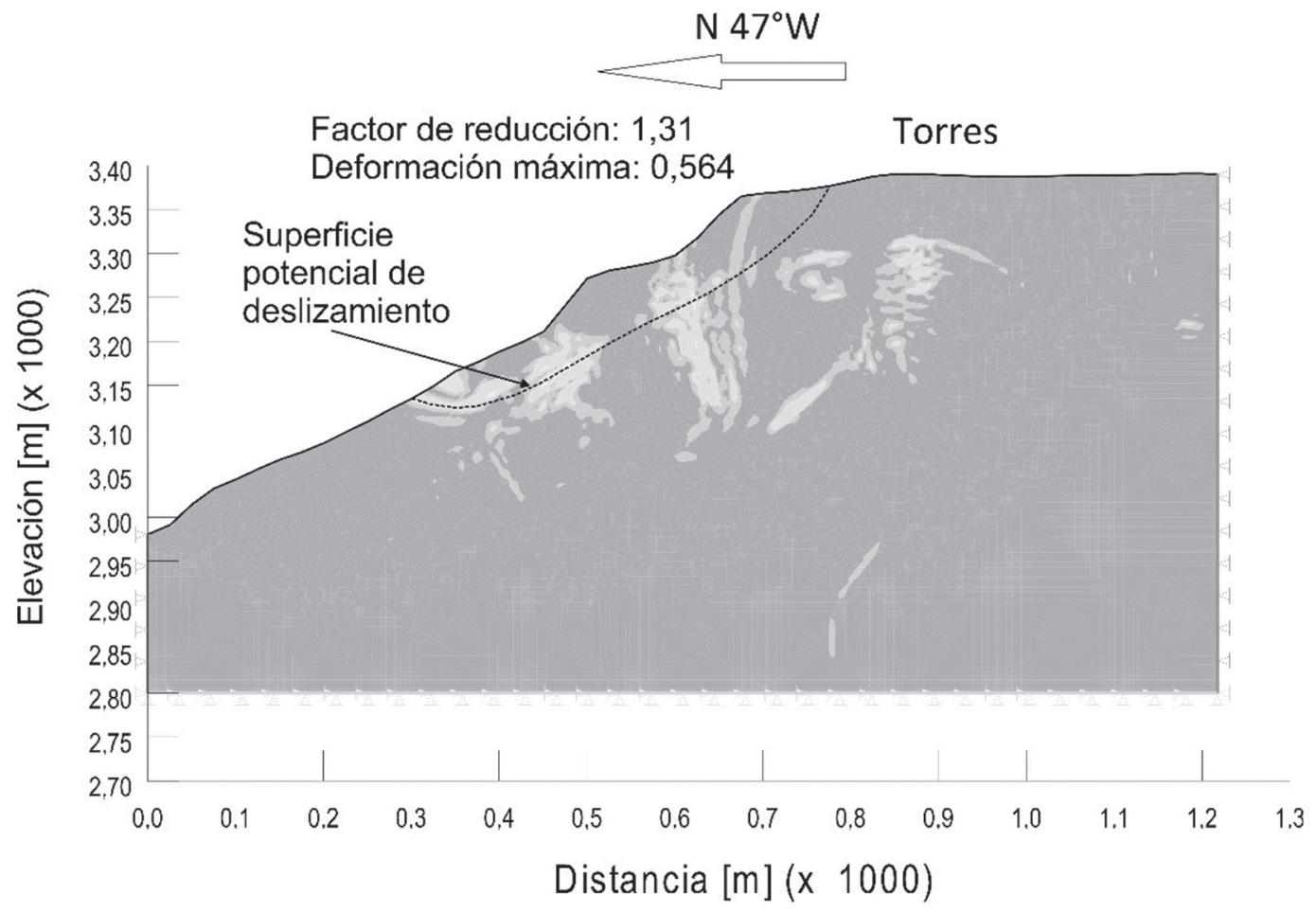

Fig. 14: Desarrollo del colapso de la ladera para un factor de reducción de 1,31.

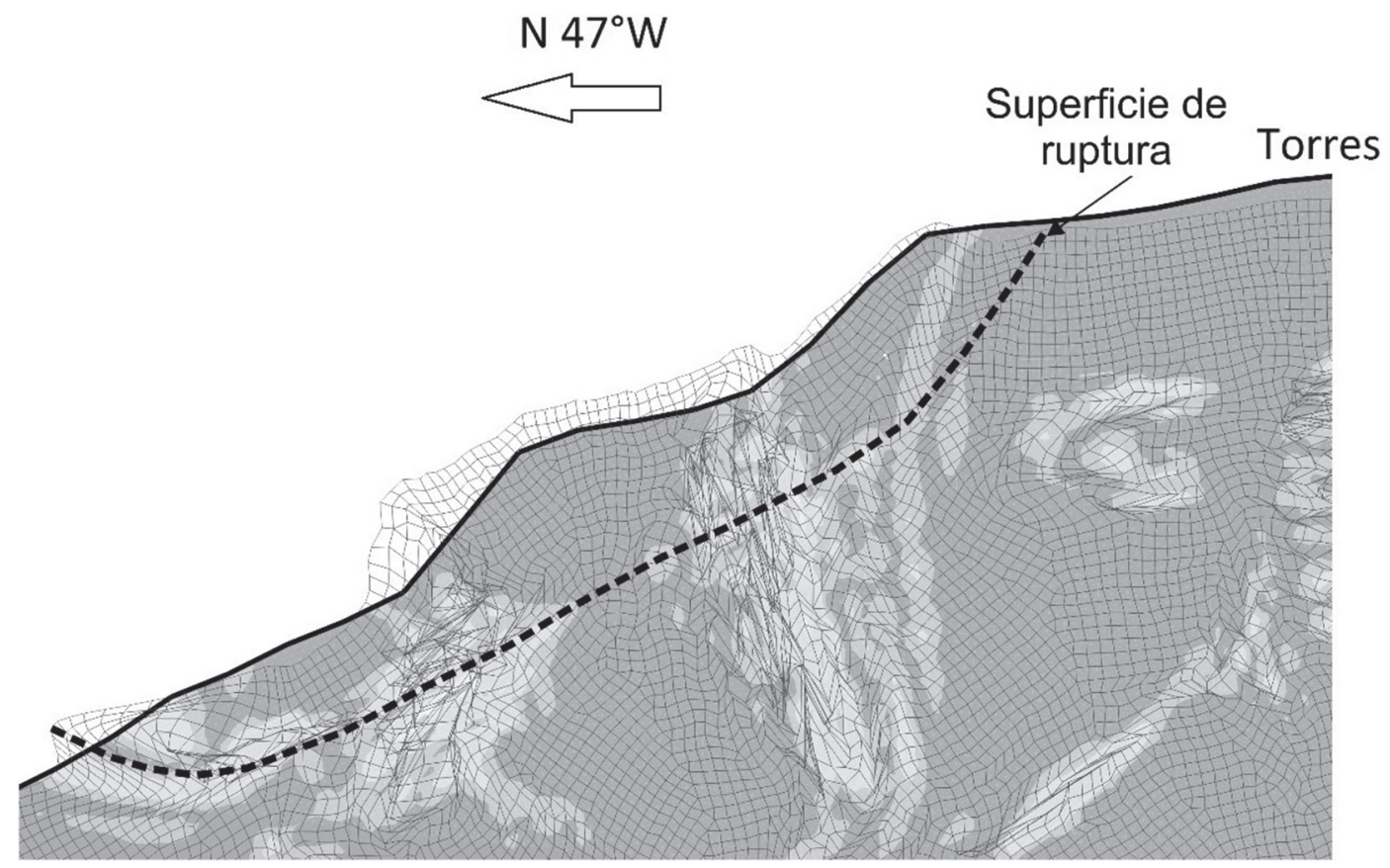

Fig. 15: Detalle del modelo donde se aprecia la deformación de la malla de elementos finitos. 
Cuadro 5

Dimensiones del deslizamiento y volumen máximo estimado.

\begin{tabular}{cc}
\hline Longitud máxima L max $[\mathrm{m}]$ & 420 \\
Ancho máximo Wmax $[\mathrm{m}]$ & 300 \\
Profundidad máxima de la superfi- & 105 \\
$\quad$ cie de ruptura Dmax $[\mathrm{m}]$ & \\
Volumen estimado $\left[\mathrm{m}^{3}\right]$ & \\
$\mathrm{V}=(\pi \mathrm{L} \max$ Wmax Dmax $) / 6$ & $\approx 7.000 .000$ \\
\hline
\end{tabular}

De acuerdo con la interpretación de las imágenes satelitales el Deslizamiento Inactivo Retes $\left(\mathrm{DI}_{\mathrm{R}}\right)$ no muestra evidencias de movimiento y se encuentra cubierto por vegetación tipo páramo y un bosque de ciprés, eucalipto y otras especies de árboles, sin embargo, luego de la inspección de campo se pudo constatar que este deslizamiento muestra evidencias de reactivación en el sector de su escarpe principal.

No se espera que la geoforma $\mathrm{D}_{\mathrm{SPD}}$ presente un movimiento hacia el suroeste en el futuro, pues en ese sentido el factor de seguridad es muy alto y el mecanismo de falla tendería a desarrollar rupturas más o menos circulares en la sección de mayor pendiente del perfil analizado, por lo cual, se descarta que esta sea la tendencia del movimiento de la geoforma $\mathrm{D}_{\mathrm{SPD}}$.

Las deformaciones mostradas por el modelo de un desprendimiento hacia el noroeste se tornan significativas una vez que a las propiedades de resistencia al corte se les aplica un factor de reducción de 1,30. El modelo no presenta convergencia a partir de un factor de reducción de 1,31, desarrollándose el colapso de la ladera, es decir, este valor del factor de reducción corresponde con el factor de seguridad de la ladera si consideramos una dirección de deslizamiento hacia el noroeste. $\mathrm{Si}$ se considera que el factor de seguridad es de 1,31 , se debe contar con un factor de disparo para que el deslizamiento se desarrolle.
El volumen estimado del deslizamiento sería de 7 millones de metros cúbicos, el cual es un volumen que se puede considerar como normal o más bien creíble para este tipo de eventos.

Es de suma importancia continuar investigando este caso de deslizamiento, en el sentido de mejorar el modelo geotécnico aquí presentado, así como, simular el tránsito de avalanchas de lodo y rocas a lo largo del cauce del río Sucio y determinar concretamente cual puede ser el sector afectado y qué implicaciones pueda tener en la Ruta 32 y el puente sobre el río antes mencionado.

Dentro de las mejoras que se deben realizar al modelo geotécnico está la definición de la red de flujo de las aguas subterráneas, con su respectivo acople mediante programas de elementos finitos, así como, incluir más investigaciones desde la perspectiva de la mecánica de suelos y rocas.

\section{REFERENCIAS BIBLIOGRÁFICAS}

Alvarado, G. (2009). Los volcanes de Costa Rica: geología, historia y riqueza natural y su gente (3 ed.). San José: EUNED.

Cruden, D. M., y Varnes, D. J. (1996). Landslides types and processes. En K. Turner y R. L. Schister (eds), Landslides: investigation and mitigation (pp. 675). Whashington, D.C: National Academy Press.

Hoek, E., Carranza-Torres, C., y Corkum, B. (2002). Hoek-Brown criterion. Presentado en el 5th North American Rock Mechanics Symposium y 17th Tunnelling Association of Canada, Toronto.

Montero, W., y Alvarado, G. E. (1995). El terremoto de patillos del 30 de diciembre de $1952(\mathrm{Ms}=5,9)$ y el contexto neotectónico 
de la región del volcán Irazú, Costa Rica. Revista Geológica América Central, 18, 25-42.

ROCSCIENCE. (2004). A new era in slope stability analysis: shear strength reduction finite element technique. Recuperado de https://www.rocscience.com/documents/ pdfs/library/StrengthReduction.pdf
ROCSCIENCE. (2007). RocLab: Rock mass strength analysis using the Hoek-Brown failure criterion (Guía del usuario del programa de cómputo RocLab 1.033). Toronto: Rocscience.

Van-Zuidam, R. A. (1986). Aerial photo interpretation in terrain analysis and geomorphologic mapping. The Netherlands: Smits Publishers. 
